\title{
Clinical features of lupus enteritis: a single-center retrospective study
}

\author{
Long Chen ${ }^{1,3+}$, Qin He ${ }^{1 \dagger}$, Man Luo', Yuxiao Gou', Dan Jiang ${ }^{1}$, Xiaoqin Zheng ${ }^{1}$, Gaowu Yan² and Fang He ${ }^{1 *}$ (D)
}

\begin{abstract}
Background: Lupus enteritis (LEn) is a rare complication of systemic lupus erythematosus (SLE). Timely diagnosis and treatment of LEn are necessary to prevent the most serious consequences - intestinal perforation, gastrointestinal bleeding, and death. We compared the clinical features of SLE patients with and without LEn.

Methods: The clinical data of LEn inpatients at Suining Central Hospital from July 2012 to June 2020 were examined. These LEn patients were matched (1:2 ratio) with concurrently hospitalized SLE patients who did not have LEn. The two groups were compared using multivariate logistic regression.

Results: We compared SLE inpatients with LEn $(n=43)$ and SLE inpatients without LEn $(n=86)$ at our institution. Multivariate logistic regression showed that ascites (odds ratio [OR]: 9.961, 95\%Cl: 2.215-44.802, $P=0.003$ ), hydronephrosis (OR: 28.060, 95\%Cl: 2.303-341.962, $P=0.009$ ), leukopenia (OR: 5.890, 95\%Cl: 1.813-19.135, $P=0.003$ ), reduced complement C3 level (OR: 4.791, 95\%Cl: 1.605-14.300, $P=0.005$ ), and elevated immunoglobin (Ig)A level (OR: 4.040, 95\%Cl: 1.307-12.487, $P=0.015)$ were independently associated with LEn. Within the LEn group, abdominal pain was the most common abdominal symptom (88.4\%), and increased mesenteric fat attenuation (74.4\%) and bowel wall thickening (58.1\%) were the most common computed tomography (CT) findings. Most LEn patients (88.4\%) required high-dose glucocorticoid therapy ( $\geq 80 \mathrm{mg}$ methylprednisolone/day), and cyclophosphamide was the most commonly used immunosuppressant (62.8\%).
\end{abstract}

Conclusions: Abdominal pain was the most common clinical symptom of LEn. Abdominal CT provides important information for detection and diagnosis of LEn. Ascites, hydronephrosis, leukopenia, hypocomplementemia (C3), and increased IgA were independently associated with LEn.

Keywords: Systemic lupus erythematosus, Lupus enteritis, Mesenteric vasculitis, Target sign, Comb sign, Abdominal pain, High-dose glucocorticoids, Immunosuppressant, Abdominal computed tomography

\section{Introduction}

Systemic lupus erythematosus (SLE) is an autoimmune disease that can damage multiple organs and organ systems. SLE-mediated damage to the digestive system can manifest as oral ulcers, pseudo intestinal obstruction,

*Correspondence: hefang2014@126.com

${ }^{\dagger}$ Long Chen and Qin He contributed equally to this work

1 Department of Rheumatology and Immunology, Suining Central

Hospital, No.127, West Desheng Rd., Chuanshan District, Suining, Sichuan Province, China

Full list of author information is available at the end of the article protein-losing enteropathy, liver damage, autoimmune pancreatitis, lupus enteritis (LEn), and other complications $[1,2]$. LEn is a rare digestive symptom complication of SLE that is also referred to as lupus mesenteric vasculitis, gastrointestinal vasculitis, or acute gastrointestinal syndrome [3]. Pain is the main abdominal symptom of LEn, and it may be accompanied by diarrhea and vomiting [4]. LEn should be suspected in SLE patients who have intestinal symptoms after exclusion of infection.

Abdominal computed tomography (CT) is the main method used to diagnose LEn. The typical CT manifestations are bowel wall thickening ("target sign") and 
mesenteric vasodilation ("comb sign") [3, 4]. Digestive endoscopy has low sensitivity in the detection of LEn, and more than half of these patients have normal endoscopy findings [4]. Pathological findings include cellular infiltration of the submucosal and muscular layers, with or without edema or vasculitis [4].

We retrospectively analyzed the clinical characteristics of 43 SLE patients with LEn and 86 SLE patients without LEn who were admitted to the inpatient division of Suining Central Hospital (Sichuan, China) to identify factors associated with LEn.

\section{Methods}

\section{Screening of the LEn and non-LEn groups}

Inpatients with LEn (LEn group) who were admitted to the Suining Central Hospital (Sichuan Province, China) from July 2012 to June 2020 were included. All patients met the criteria for LEn provided in the 1997 classification of SLE by the American College of Rheumatology (ACR) [5] and also had the following three conditions: (i) abdominal symptoms and at least one of the following: abdominal pain, diarrhea, bloating, nausea, or vomiting; (ii) at least one of the following three imaging manifestations: bowel wall thickening, mesenteric vasodilation, or increased attenuation of mesenteric fat $[3,4,6]$; and (iii) no relief from digestive symptoms following use of acid inhibitors, mucosal protective agents, gastrointestinal motility drugs, or antibiotics, but successful alleviation after use of an increased dosage of glucocorticoids. Then, two non-LEn patients were selected to match with each LEn patient in the consecutive series. All patients in the non-LEn group were also inpatients who met the 1997 classification of SLE from the ACR (Fig. 1).

\section{Data collection}

The following parameters were recorded for each patient in both groups: age; sex; disease course; age at disease onset; presence of pleural effusion, pericardial effusion, ascites, hydronephrosis, fever, arthritis/arthralgia, skin rash, lupus nephritis, leukopenia, anemia, and thrombocytopenia; hypocomplementemia $(\mathrm{C} 3, \mathrm{C} 4)$; levels of immunoglobulin (Ig) A, IgG, and IgM; and results of an autoantibody panel. Pleural effusion, pericardial effusion, and ascites were confirmed by ultrasonography or CT. An axillary temperature above $37.5^{\circ} \mathrm{C}$ was considered to be elevated. Skin rashes were classified as butterfly rash, discoid rash, vasculitis-like rash, erythema hyperemia, or frostbite-like rash. Lupus nephritis was defined by a 24-h urinary protein level (total urine protein) above $0.5 \mathrm{~g}$ or positive biopsy results. A white blood cell count below $3.5 \times 10^{9} / \mathrm{L}$ was considered leukopenia; a hemoglobin level below $110 \mathrm{~g} / \mathrm{L}$ (females) or below $120 \mathrm{~g} / \mathrm{L}$ (males) was considered anemia; a total platelet count below

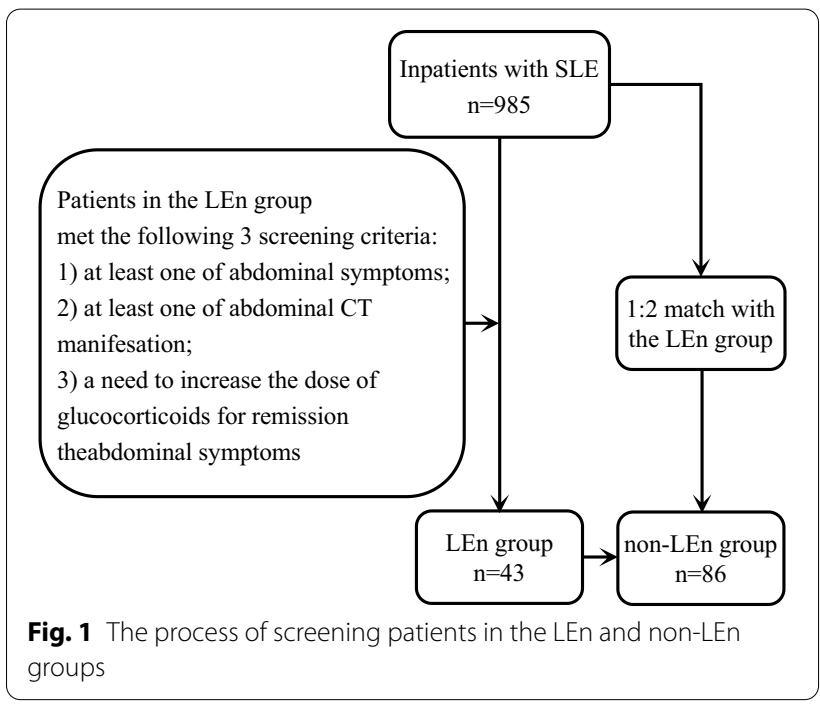

$100 \times 10^{9} / \mathrm{L}$ was considered thrombocytopenia; a plasma albumin level below $40.0 \mathrm{~g} / \mathrm{L}$ was considered hypoalbuminemia; a C3 level below $0.7 \mathrm{~g} / \mathrm{L}$ and a C4 level below $0.1 \mathrm{~g} / \mathrm{L}$ were considered low; and increased Ig levels were above $4.2 \mathrm{~g} / \mathrm{L}$ for IgA, $17.4 \mathrm{~g} / \mathrm{L}$ for IgG, and $2.8 \mathrm{~g} / \mathrm{L}$ for IgM.

An indirect immunofluorescence assay was used to detect anti-ds-DNA antibody and immunoblotting was used to detect anti-nucleosome antibody, anti-ribosomal $\mathrm{P}$ protein antibody, anti-histone antibody, anti-Smith antibody, anti-SSA antibody, anti-SSB antibody, and antiproliferating cell nuclear antigen antibody. For all the patients in the LEn group, abdominal symptoms (pain, diarrhea, bloating, nausea, and vomiting), abdominal CT findings (bowel wall thickening, comb sign, increased attenuation of mesenteric fat, bowel distension, and ascites), and drug regimens (maximum dosage of glucocorticoids and use of immunosuppressants, intravenous gamma globulin, and antibiotics) were recorded.

\section{Follow-up of the LEn group}

Only patients in the LEn group were followed up, and the two endpoints were patient survival as of the last followup and relapse of LEn. Follow-up consisted of inquiries using the hospital information system and direct telephone contact with the patient or relatives to determine the occurrence of wither endpoint. The cut-off date for the follow-up was 31 January 2021.

\section{Statistical analysis}

Continuous variables are reported as mean \pm standard deviation (SD) or median (interquartile range, IQR) and were compared by using a Student's $t$-test or the MannWhitney $U$ test, as appropriate. Discrete variables are 
presented as the frequency (percentage) and were compared using the chi-square test or Fisher's exact test. Variables in which the univariate analysis indicated the significance of the difference was below 0.2 were included in multivariate logistic regression analysis (forward selection method) to screen for factors independently associated with LEn. All data analyses were performed using SPSS version 22.0 (IBM, Armonk, NY). For all statistical analyses, differences were deemed statistically significant when the two-sided $P$ value was below 0.05 .

\section{Results}

\section{Screening of the LEn and non-LEn groups}

A total of 985 individuals with SLE were inpatients at our hospital from July 2012 to June 2020. After screening for eligibility, we examined 43 patients in the LEn group and 86 matched patients in the non-LEn group. The overall incidence of LEn among SLE patients at our institution was approximately $4.4 \%$ (Fig. 1 ).

\section{Comparisons of clinical data in the LEn and non-LEn groups}

The comparison of general information (the sex ratio, age at screening, age of onset and course of the disease) collected from these two groups of patients indicated no significant difference. This indicated these two groups were comparable, and allowed us to perform meaningful comparisons of other clinical data (Table 1).

Comparisons of the clinical data in the two groups showed that pleural effusion, ascites, hydronephrosis, skin rash, lupus nephritis, leukopenia, hypoalbuminemia, hypocomplementemia (C3 and C4), increased IgA level, and positivity for anti-nucleosome-ANA antibodies were significantly more common in the LEn group (all $P<0.05$; Table 2).

\section{Analysis of factors associated with LEn}

We used multivariable analysis with forward selection to further analyze variables that had $P$ values were below 0.2

Table 1 General information of the LE and non-LEn groups

\begin{tabular}{llll}
\hline & LE group & Non-LEn group & P-value \\
\hline Male sex $n(\%)$ & $5(11.63)$ & $3(3.49)$ & $0.116^{\mathrm{c}}$ \\
Age at screening (years) $^{\mathrm{a}}$ & $40.0(19.0)$ & $39.5(23.2)$ & $0.719^{\mathrm{d}}$ \\
Disease duration (years) $^{\mathrm{a}}$ & $3.0(7.7)$ & $3.7(7.1)$ & $0.589^{\mathrm{d}}$ \\
Age of disease onset(years) $^{\mathrm{b}}$ & $33.2 \pm 11.5$ & $32.8 \pm 13.6$ & $0.201^{\mathrm{e}}$ \\
\hline
\end{tabular}

${ }^{a}$ Median (interquartile range, IQR)

${ }^{\mathrm{b}}$ Mean \pm standard deviation (SD)

'Fisher's exact test;

${ }^{d}$ Mann-Whitney $U$ test

e Student's t test in the analysis above. The results indicated that ascites, hydronephrosis, leukopenia, decreased C3 level, and increased IgA level were independently associated with LEn (Table 3).

\section{Gastrointestinal symptoms and imaging manifestations in patients with LEn}

The common abdominal symptoms in patients with LEn were abdominal pain $(38 / 43,88.4 \%)$, nausea $(23 / 43$, $53.5 \%)$, vomiting $(21 / 43,48.8 \%)$, abdominal distension $(21 / 43,48.8 \%)$, and diarrhea $(17 / 43,39.5 \%)$. Abdominal CT findings showed that more than half of patients with LEn had increased attenuation of mesenteric fat (32/43, $74.4 \%)$ and bowel wall thickening $(25 / 43,58.1 \%)$, although the mesenteric vasodilation $(11 / 43,25.6 \%)$ and ascites $(12 / 43,27.9 \%)$ were less common (Table 4, Fig. 2).

\section{Treatment and follow-up}

All LEn patients received intravenous methylprednisolone to induce remission, with a minimum dosage of $40 \mathrm{mg} /$ day. Thirty-six patients $(36 / 43,83.7 \%)$ received combined immunosuppressive therapy (intravenous of cyclophosphamide at $0.5-1.0 \mathrm{mg} / \mathrm{m}^{2} /$ month or oral mycophenolate mofetil at $1.5-2.0 \mathrm{~g} /$ day) after LEn remission. Among these 36 patients, the major systemic lesions were lupus nephritis (19/43, 44.2\%), neuropsychiatric lupus $(5 / 43,11.6 \%)$, autoimmune hemolytic anemia (3/43, 7.0\%), diffuse alveolar hemorrhage (1/43, 2.3\%), and lupus hepatitis $(1 / 43,2.3 \%)$. Approximately half of the patients with LEn $(23 / 43,53.5 \%)$ also received antibiotics during treatment, and 7 patients $(7 / 43,16.3 \%)$ received intravenous Ig (IVIG) (Table 4).

The median follow-up time in the LEn group was 58 months (range: 14-92 months). During follow-up, one LEn patient died of Pneumocystis carinii pneumonia (patient no. 16, Additional file 1: Table 1; Additional file 2: Figure 1) and one patient had LEn recurrence (identified as patient no. 23 and also as patient no. 40; Additional file 1: Table 1).

\section{Discussion}

SLE is a relatively common autoimmune disease that can affect many organs. Organ damage mediated by autoantibodies and autoreactive $\mathrm{T}$ lymphocytes are the main features of SLE. The clinical manifestations are highly heterogeneous, and SLE affects many organ systems throughout the body [7]. Damage to the digestive system is very common in these patients because the SLE itself can lead to recurrent oral mucosal ulcers, lupus hepatitis, autoimmune pancreatitis, proteinlosing enteropathy, and LEn. Moreover, gastrointestinal reactions and liver dysfunction can be caused by the use of non-steroidal anti-inflammatory agents, 
Table 2 Baseline characteristics of the LE and non-LEn groups

\begin{tabular}{|c|c|c|c|c|}
\hline & $\begin{array}{l}\text { LE group } \\
\text { n (\%) }\end{array}$ & $\begin{array}{l}\text { Non-LEn group } \\
\mathrm{n}(\%)\end{array}$ & $x^{2}$ & $P$ value \\
\hline \multicolumn{5}{|l|}{ Clinical manifestations } \\
\hline Pericardial effusion & $7(16.3)$ & $14(16.3)$ & 0 & $1.000^{\mathrm{a}}$ \\
\hline Pleural effusion & $15(34.9)$ & $14(16.3)$ & 5.694 & $0.017^{\mathrm{a}}$ \\
\hline Ascites & $12(27.9)$ & $3(3.5)$ & 16.634 & $<0.001^{\mathrm{a}}$ \\
\hline Hydronephrosis & $6(14.0)$ & $1(1.2)$ & - & $0.003^{b}$ \\
\hline Fever & $10(23.3)$ & $16(18.6)$ & 0.385 & $0.535^{\mathrm{a}}$ \\
\hline Arthritis/arthralgia & $14(32.6)$ & $20(23.3)$ & 1.278 & $0.258^{\mathrm{a}}$ \\
\hline Rash & $18(41.9)$ & $21(24.4)$ & 4.135 & $0.042^{\mathrm{a}}$ \\
\hline Lupus nephrits & $19(44.2)$ & $22(25.6)$ & 4.576 & $0.032^{\mathrm{a}}$ \\
\hline \multicolumn{5}{|l|}{ Biological features } \\
\hline Leukopenia & $10(23.3)$ & $8(9.3)$ & 4.649 & $0.031^{\mathrm{a}}$ \\
\hline Anaemia & $24(55.8)$ & $38(44.2)$ & 1.553 & $0.213^{\mathrm{a}}$ \\
\hline Thrombocytopenia & $12(27.9)$ & $17(19.8)$ & 1.090 & $0.297^{\mathrm{a}}$ \\
\hline Hypoalbuminemia & $30(69.8)$ & $35(40.7)$ & 9.691 & $0.002^{\mathrm{a}}$ \\
\hline \multicolumn{5}{|l|}{ Immunological features } \\
\hline Hypocomplementemia (C3) & $37(86.0)$ & $44(51.2)$ & 14.931 & $<0.001^{\mathrm{a}}$ \\
\hline Hypocomplementemia (C4) & $23(53.5)$ & $26(30.2)$ & 6.582 & $0.010^{\mathrm{a}}$ \\
\hline Elevated IgA & $13(30.2)$ & $12(14.0)$ & 4.862 & $0.027^{\mathrm{a}}$ \\
\hline Elevated lgG & $12(27.9)$ & $28(32.6)$ & 0.290 & $0.590^{\mathrm{a}}$ \\
\hline Elevated IgM & $0(0.0)$ & $4(4.7)$ & - & $0.302^{b}$ \\
\hline Anti-ds-DNA & $19(44.2)$ & $26(30.2)$ & 2.457 & $0.117^{\mathrm{a}}$ \\
\hline Anti-nu antibody positivity & $18(41.9)$ & $19(22.1)$ & 5.476 & $0.019^{a}$ \\
\hline Anti-PP antibody positivity & $20(46.5)$ & $25(29.1)$ & 3.839 & $0.050^{\mathrm{a}}$ \\
\hline Anti-P antibody positivity & $14(32.6)$ & $15(17.4)$ & 3.759 & $0.053^{\mathrm{a}}$ \\
\hline Anti-Sm antibody positivity & $13(30.2)$ & $17(19.8)$ & 1.759 & $0.185^{\mathrm{a}}$ \\
\hline Anti-PCNA antibody positivity & $1(2.3)$ & $1(1.2)$ & - & $1.000^{b}$ \\
\hline Anti-SSA antibody positivity & $34(79.1)$ & $57(66.3)$ & 2.257 & $0.133^{\mathrm{a}}$ \\
\hline Anti-SSB antibody positivity & $8(18.6)$ & $17(19.8)$ & 0.025 & $0.875^{\mathrm{a}}$ \\
\hline
\end{tabular}

Anti-ds-DNA, anti-double-stranded DNA; Anti-nu, anti-nucleosome; Anti-P, anti-histone antibody; Anti-PCNA, anti-proliferating cell nuclear antigen; Anti-PP, antiribosomal P protein; Ig: immunoglobulin

${ }^{\text {a }}$ Chi-square test

${ }^{\mathrm{b}}$ Fisher's exact test

Table 3 Screening independent associated factors of LEn by multivariate logistic regression analysis (forward method)

\begin{tabular}{llllc}
\hline & B & SE & $\boldsymbol{P}$-value & OR (95\%Cl) \\
\hline Ascites & 2.299 & 0.767 & 0.003 & $9.961(2.215-44.802)$ \\
Hydronephrosis & 3.334 & 1.276 & 0.009 & $28.060(2.303-341.962)$ \\
Leukopenia & 1.773 & 0.601 & 0.003 & $5.890(1.813-19.135)$ \\
Hypocomple- & 1.567 & 0.558 & 0.005 & $4.791(1.605-14.300)$ \\
mentemia (C3) & & & & \\
Increased lgA & 1.396 & 0.576 & 0.015 & $4.040(1.307-12.487)$ \\
\hline
\end{tabular}

$95 \% \mathrm{Cl}, 95 \%$ confidence interval; $\mathrm{B}$, coefficient value; IgA, immunoglobulin $\mathrm{A}$; $\mathrm{OR}$, odds ratio; $\mathrm{SE}$, standard error glucocorticoids, immunosuppressants, and other drugs $[1,2,8-12]$. LEn is a rare disease that is secondary to SLE whose incidence varies according to geography and race. A literature review by Ju et al. [3] reported that the global incidence of LEn in SLE patients was approximately 0.2 to $9.7 \%$.

The risk factors for the LEn among SLE patients have not been fully delineated. Lee et al. [13] analyzed 175 SLE patients and assigned them to three groups: (i) SLE + LEn with abdominal pain, (ii) SLE alone with abdominal pain, and (iii) SLE alone without abdominal pain. They showed that leukopenia was more common in the first group than in the other two groups, in agreement with our findings. A reduced level of complement C3 is often a sensitive indicator of active SLE. 
Table 4 Clinical manifestation and treatment in the LEn group

\begin{tabular}{lr}
\hline Clinical manifestation/treatment & $\mathbf{n}(\%)$ \\
\hline Gastrointestinal symptoms & $38(88.4)$ \\
Abdominal pain & $21(48.8)$ \\
Diarrhea & $21(48.8)$ \\
Abdominal distension & $23(53.5)$ \\
Nausea & $17(39.5)$ \\
Vomiting & \\
CT manifestation & $25(58.1)$ \\
Bowel wall thickening & $11(25.6)$ \\
Engorgement of mesenteric vessels & $32(74.4)$ \\
Increased attenuation of mesenteric fat & $17(39.5)$ \\
Bowel dilatation & $12(27.9)$ \\
Ascites & \\
Therapeutic intervention & $38(88.4)$ \\
Glucocorticoid (MP $\geq 80$ mg/day) & \\
Immunosuppressant & $27(62.8)$ \\
CTX & $9(20.9)$ \\
MMF & $7(16.3)$ \\
IVIG & $23(53.5)$ \\
Antibiotics &
\end{tabular}

CTX, cyclophosphamide; IVIG, intravenous immunoglobulin; MMF, mycophenolate mofetil; MP, methylprednisolone

We found that a reduced C3 level was more common in SLE patients with LEn than in those without LEn. However, previous studies [13, 14] reported inconsistent findings regarding the association between LEn and active SLE. Buck et al. [14] reported that lupus mesenteric vasculitis occurred only in patients with active disease (SLE disease activity index [SLEDAI] score $>8$ ), but Lee et al. [13] showed that the SLEDAI score did not differ significantly between SLE patients with abdominal pain and LEn and SLE patients with abdominal pain but no LEn. Their findings [13] suggested that the SLEDAI score may be unsuitable for disease assessment and treatment decisions in patients with LEn. Some other studies reported the co-occurrence of lupus-related urinary system damage and LEn [15-18], and the manifestations of urinary tract damage in these patients included hydronephrosis and lupus cystitis. Approximately $14.0 \%(6 / 43)$ of the patients in our LEn group had hydronephrosis, significantly more than in the non-LEn group. Our multivariate regression analysis confirmed that hydronephrosis was significantly and independently associated with LEn, consistent with the conclusions in several previous studies [15-18].

Interestingly, few previous studies have examined the serum levels of IgA, IgG, and IgM in patients with LEn. We found that the level of serum IgA was significantly greater in the LEn group than in the non-LEn group, and our multivariate regression analysis showed that an increased level of serum IgA was associated with LEn. IgA functions in the mucosal immune barrier and in resistance to pathogenic microorganisms. The intestine is the largest human organ with mucosal tissues, and is the main organ that produces and secretes IgA. IgA also plays an important role in maintaining the stability of intestinal microecology $[19,20]$. Hence, the connection between increased IgA level and LEn seems biologically plausible, but further studies are necessary to confirm the clinical significance and underlying mechanisms.

Similar to the findings of previous studies [11-16], the clinical symptoms in our LEn patients were not specific, and abdominal pain was the most common symptom. Approximately $90 \%$ of our LEn patients had abdominal pain of varying severity, and some patients also had nausea, abdominal distension, diarrhea, and vomiting. Clinicians may suspect LEn when abdominal symptoms occur in SLE patients, and this highlights the need for timely abdominal CT, especially enhanced abdominal CT which is more sensitive in the detection of intestinal abnormalities. There are three typical abdominal CT findings in patients with LEn, and these can appear alone or concurrently: $(i)$ bowel wall thickening $(>3.0 \mathrm{~mm})$, which leads to separation of the mucosa and muscle layers and appearance of the "target sign"; (ii) mesenteric vasodilation with appearance of the "comb sign"; and (iii) increased attenuation of mesenteric fat [16, 21-25]. The co-occurrence of the "target sign" and "comb sign" is particularly specific to LEn, and can be used to establish a diagnosis. In addition to CT manifestations, ultrasonography and magnetic resonance enterography (MRE) can also be used to diagnose LEn. For example, Demiselle et al. [26] described a patient with LEn who had characteristic intestinal wall edema and ascites based on ultrasonography. Cicero et al. [27] used MRE to observe a formation with the appearance of a thumb print caused by bowel ischemia and bowel wall edema in a patient with LEn.

Due to the lack of prospective randomized controlled clinical trials, there are currently no available guidelines or recommendations for the treatment of LEn. However, previous studies $[3,4]$ reported that most LEn patients achieved remission following high-dose glucocorticoids, with or without the addition of immunosuppressive therapy. The major immunosuppressants used in these patients are cyclophosphamide, azathioprine, and mycophenolate mofetil [4]. Early case reports found that most patients with LEn received glucocorticoids with cyclophosphamide [28-30]. Lian et al. [31] retrospectively analyzed patients with SLE and acute gastrointestinal syndrome and showed that the combined use of cyclophosphamide and glucocorticoids significantly 

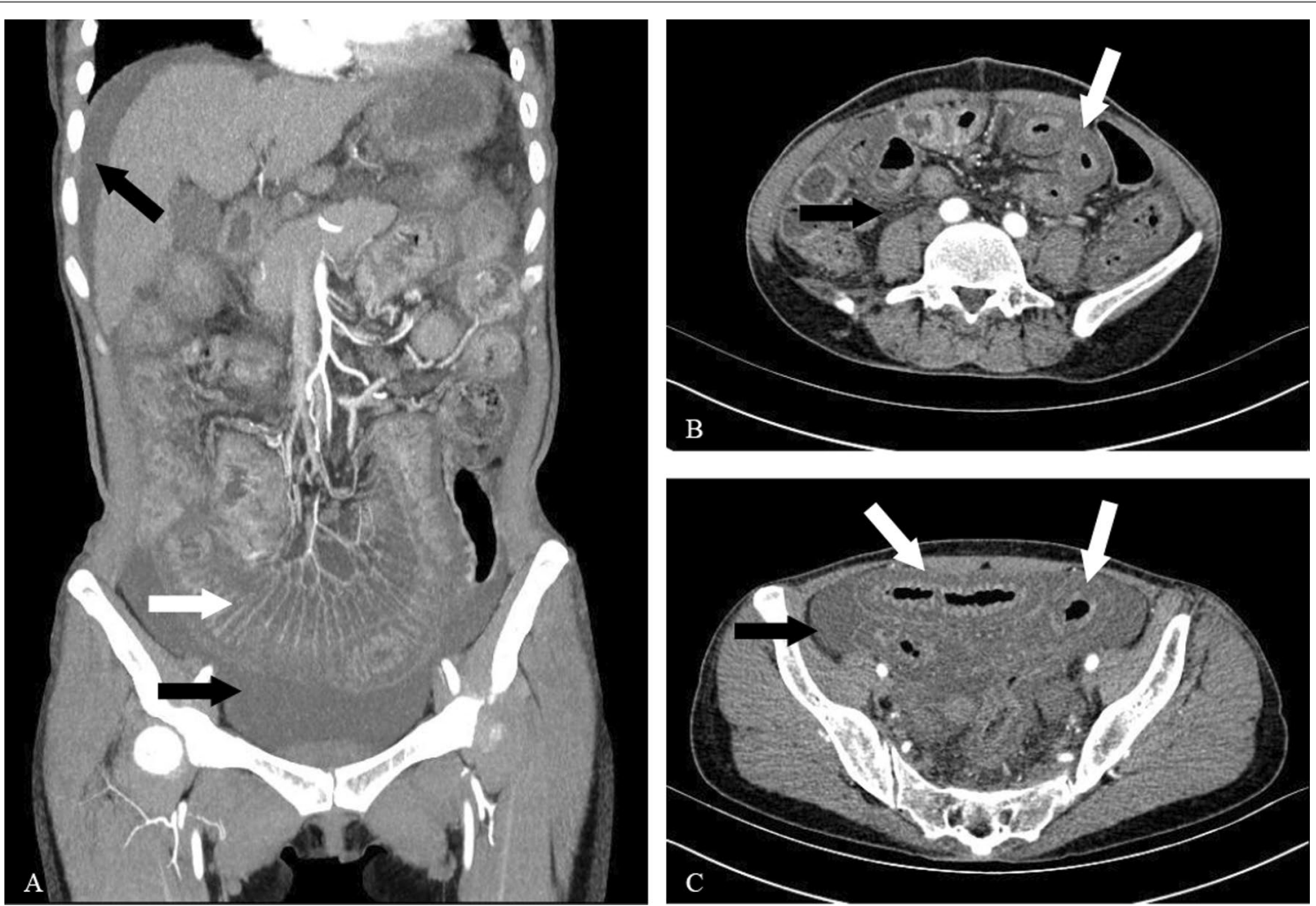

Fig. 2 The CT manifestation of lupus enteritis. A: massive fluid in the abdominal cavity (the black arrow) and engorgement of mesenteric vessels (comb sign, the white arrow); $\mathbf{B}$ : increased attenuation of mesenteric fat (the black arrow) and the bowel wall thickening (target sign, the white arrow); C: massive fluid in the abdominal cavity (the black arrow), the bowel wall thickening and bowel dilatation (the white arrow)

improved patient prognosis. In our study, all patients with LEn were relieved of abdominal symptoms by highdose glucocorticoids. However, there are no guidelines regarding the use of immunosuppressive agents combined with glucocorticoids for these patients. In clinical practice, a comprehensive assessment of the patient's complications, such lupus nephritis, neuropsychiatric lupus, and other important organ damage, is necessary to guide treatment decisions, such as combined immunosuppressive therapy. About half of our LEn patients also had active lupus nephritis, and some other patients had neuropsychiatric lupus, autoimmune hemolytic anemia, diffuse alveolar hemorrhage, and other complications. Hence, more than half of our patients with LEn received glucocorticoids in combination with cyclophosphamide. Approximately $20.9 \%$ of these patients received mycophenolate with glucocorticoids, and $16.3 \%$ received glucocorticoids alone.

Death from LEn is rare, and only one patient in our LEn group died during the follow-up. This patient had recurrent abdominal pain for more than two months that was rapidly relieved by treatment with high-dose glucocorticoids with cyclophosphamide, but she unfortunately died of Pneumocystis carinii pneumonia. In addition, only one of our patients experienced LEn recurrence. This patient initially received glucocorticoids alone to induce remission, but received combined treatment with glucocorticoids and cyclophosphamide after recurrence. Maruyama et al. [32] showed that LEn was likely to recur, and reported that $29 \%(5 / 17)$ of their LEn patients experienced recurrence. These authors suggested that bowel wall thickness exceeding $9.0 \mathrm{~mm}$ may be a predictor of recurrence. They also reported [32] that among the 5 patients with recurrence, 2 patients initially received glucocorticoids alone.

Our study was limited by the small sample size and the single-center and retrospective design. Because it was a retrospective study, there were some missing data that made it impossible to analyze certain data, such as antiphospholipid antibodies and intestinal ultrasound results. Second, due to our lack of baseline data (before onset of LEn), we could not make predictions about related risk factors. Therefore, further studies of the clinical characteristics of LEn should use a larger more rigorous prospective cohort design, or even a multi-center randomized controlled clinical trial. 


\section{Conclusions}

LEn is a rare complication of SLE, and abdominal pain is the most common clinical symptom. Abdominal CT should be performed in SLE patients who report abdominal pain to confirm the presence of LEn, especially in patients who have other factors independently associated with LEn. Timely administration of high-dose glucocorticoid therapy is effective and can improve the prognosis of these patients. The decision of whether to combine a glucocorticoid with an immunosuppressive agent requires comprehensive consideration of the comorbidities of individual LEn patients. More high-quality registration studies are needed to focus on this rare complication of SLE.

\section{Supplementary Information}

The online version contains supplementary material available at https://doi. org/10.1186/s13023-021-02044-4.

Additional file 1: Table 1. Abdominal symptoms, CT manifestations, and treatments of patients with lupus enteritis.

Additional file 2: Figure 1. Lung CT results in the patient with lupus enteritis who died from Pneumocystis carinii pneumonia.

\section{Acknowledgements}

We thank the editor and two reviewers for their constructive comments and suggestions and Dr. Morgan A McClurefor (Department of Radiology and Imaging; Institute of Rehabilitation and Development of Brain Function, The Second Clinical Medical College of North Sichuan Medical College Nanchong Central Hospital) for linguistic assistance.

\section{Authors' contributions}

$\mathrm{CL}$ and $\mathrm{HQ}$ completed the research design, data analysis and manuscript writing; LM, G-YX, JD and Z-XQ completed the collection and arrangement of clinical data; Y-GW was responsible for the analysis of imaging data and the provision of imaging data; HF completed the study design and manuscript review and proofreading. All authors read and approved the final manuscript.

\section{Funding}

This research did not receive any specific grant from funding agencies in the public, commercial, or nonprofit sectors.

\section{Availability of data and materials}

The datasets used and/or analyzed during the current study are available from the corresponding author on reasonable request.

\section{Declarations}

Ethics approval and consent to participate

This study was conducted in accordance with Helsinki Declaration, and it was approved by the Ethics Committee for Scientific Research of Suining Central Hospital. All subjects participating in the study gave written informed consent.

\section{Consent for publication}

All authors read the final manuscript and approved it for publication.

\section{Competing interests}

The authors declare that they have no competing interests.

\section{Author details}

${ }^{1}$ Department of Rheumatology and Immunology, Suining Central Hospital, No.127, West Desheng Rd., Chuanshan District, Suining, Sichuan Province,
China. ${ }^{2}$ Department of Radiology, Suining Central Hospital, No.127, West Desheng Rd., Chuanshan District, Suining, Sichuan Province, China. ${ }^{3}$ Department of Scientific Research Management, Suining Central Hospital, No.127, West Desheng Rd., Chuanshan District, Suining, Sichuan Province, China.

Received: 23 April 2021 Accepted: 19 September 2021

Published online: 26 September 2021

\section{References}

1. Tian XP, Zhang X. Gastrointestinal involvement in systemic lupus erythematosus: insight into pathogenesis, diagnosis and treatment. World J Gastroenterol. 2010;16(24):2971-7.

2. Brewer BN, Kamen DL. Gastrointestinal and hepatic disease in systemic lupus erythematosus. Rheum Dis Clin North Am. 2018;44(1):165-75.

3. Ju JH, Min JK, Jung CK, Oh SN, Kwok SK, Kang KY, Park KS, Ko HJ, Yoon CH, Park SH, Cho CS, Kim HY. Lupus mesenteric vasculitis can cause acute abdominal pain in patients with SLE. Nat Rev Rheumatol. 2009;5:273-81.

4. Janssens P, Arnaud L, Galicier L, Mathian A, Hie M, Sene D, Haroche J, Veyssier-Belot C, Huynh-Charlier I, Grenier PA, Piette JC, Amoura Z. Lupus enteritis: from clinical findings to therapeutic management. Orphanet J Rare Dis. 2013;8:67

5. Hochberg MC. Updating the American College of Rheumatology revised criteria for the classification of systemic lupus erythematosus. Arthritis Rheum. 1997:40:1725.

6. Isenberg DA, Rahman A, Allen E, Farewell V, Akil M, Bruce IN, D'Cruz D, Griffiths B, Khamashta M, Maddison P, McHugh N, Snaith M, Teh LS, Yee CS, Zoma A, Bilag GC 2004. Development and initial validation of an updated version of the British Isles Lupus Assessment Group's disease activity index for patients with systemic lupus erythematosus. Rheumatology Oxford. 2005; 44(7):902-906.

7. Tsokos GC. Systemic lupus erythematosus. N Engl J Med. 2011:365(22):2110-2021.

8. Ebert EC, Hagspiel KD. Gastrointestinal and hepatic manifestations of systemic lupus erythematosus. J Clin Gastroenterol. 2011;45(5):436-41.

9. Sönmez HE, Karhan AN, Batu ED, Bilginer Y, Gümüş E, Demir H, Yüce A, Özen S. Gastrointestinal system manifestations in juvenile systemic lupus erythematosus. Clin Rheumatol. 2017;36(7):1521-6.

10. Tahernia L, Alimadadi H, Tahghighi F, Amini Z, Ziaee V. Frequency and type of hepatic and gastrointestinal involvement in juvenile systemic lupus erythematosus. Autoimmune Dis. 2017;2017:8097273.

11. Li Z, Xu D, Wang Z, Wang Y, Zhang S, Li M, Zeng X. Gastrointestinal system involvement in systemic lupus erythematosus. Lupus. 2017;26(11):1127-38

12. Kröner PT, Tolaymat OA, Bowman AW, Abril A, Lacy BE. Gastrointestinal manifestations of rheumatological diseases. Am J Gastroenterol. 2019:114(9):1441-54.

13. Lee CK, Ahn MS, Lee EY, Shin JH, Cho YS, Ha HK, Yoo B, Moon HB. Acute abdominal pain in systemic lupus erythematosus: focus on lupus enteritis (gastrointestinal vasculitis). Ann Rheum Dis. 2002;61(6):547-50.

14. Buck AC, Serebro LH, Quinet RJ. Subacute abdominal pain requiring hospitalization in a systemic lupus erythematosus patient: a retrospective analysis and review of the literature. Lupus. 2001:10(7):491-5.

15. Yuan S, Ye Y, Chen D, Qiu Q, Zhan Z, Lian F, Li H, Liang L, Xu H, Yang X. Lupus mesenteric vasculitis: clinical features and associated factors for the recurrence and prognosis of disease. Semin Arthritis Rheum. 2014;43(6):759-66.

16. Chu YC, Hsu BB, Tseng KC. Lupus mesenteric vasculitis with $\mathrm{Gl}$ and genitourinary tract involvement. Clin Gastroenterol Hepatol. 2014;12(8):e6970 (quiz e71-2, e73).

17. Koh JH, Lee J, Jung SM, Ju JH, Park SH, Kim HY, Kwok SK. Lupus cystitis in Korean patients with systemic lupus erythematosus: risk factors and clinical outcomes. Lupus. 2015;24(12):1300-7.

18. Yagita M, Tsujimoto K, Yagita M, Fujita M. Atypical presenting symptoms of acute onset systemic lupus erythematosus with enteritis and cystitis. Case Rep Med. 2016;2016:8579812.

19. Macpherson AJ, Yilmaz B, Limenitakis JP, Ganal-Vonarburg SC. IgA Function in relation to the intestinal microbiota. Annu Rev Immunol. 2018:36:359-81. 
20. Tezuka H, Ohteki T. Regulation of IgA production by intestinal dendritic cells and related cells. Front Immunol. 2019;10:1891.

21. Goh YP, Naidoo P, Ngian GS. Imaging of systemic lupus erythematosus. Part II: gastrointestinal, renal, and musculoskeletal manifestations. Clin Radiol. 2013:68(2):192-202.

22. Lin HP, Wang YM, Huo AP. Severe, recurrent lupus enteritis as the initial and only presentation of systemic lupus erythematosus in a middle-aged woman. J Microbiol Immunol Infect. 2011;44(2):152-5.

23. Smith LW, Petri M. Lupus enteritis: an uncommon manifestation of systemic lupus erythematosus. J Clin Rheumatol. 2013;19(2):84-6.

24. Sran S, Sran M, Patel N, Anand P. Lupus enteritis as an initial presentation of systemic lupus erythematosus. Case Rep Gastrointest Med. 2014;2014:962735.

25. Alves SC, Fasano S, Isenberg DA. Autoimmune gastrointestinal complications in patients with systemic lupus erythematosus: case series and literature review. Lupus. 2016;25(14):1509-19.

26. Demiselle J, Sayegh J, Cousin M, Olivier A, Augusto JF. An unusual cause of abdominal pain: lupus enteritis. Am J Med. 2016;129(5):e11-2.

27. Cicero G, Blandino A, D'Angelo T, Bottari A, Cavallaro M, Ascenti G, Mazziotti S. Magnetic resonance enterography appraisal of lupus enteritis: a case report. Radiol Case Rep. 2018;13(5):915-9.
28. Laing TJ. Gastrointestinal vasculitis and pneumatosis intestinalis due to systemic lupus erythematosus: successful treatment with pulse intravenous cyclophosphamide. Am J Med. 1988;85(4):555-8.

29. Turner HE, Myszor MF, Bradlow A, David J. Lupus or lupoid hepatitis with mesenteric vasculitis. Br J Rheumatol. 1996;35(12):1309-11.

30. Grimbacher B, Huber M, von Kempis J, Kalden P, Uhl M, Köhler G, Blum $\mathrm{HE}$, Peter HH. Successful treatment of gastrointestinal vasculitis due to systemic lupus erythematosus with intravenous pulse cyclophosphamide: a clinical case report and review of the literature. Br J Rheumatol. 1998;37(9):1023-8.

31. Lian TY, Edwards CJ, Chan SP, Chng HH. Reversible acute gastrointestinal syndrome associated with active systemic lupus erythematosus in patients admitted to hospital. Lupus. 2003;12(8):612-6.

32. Maruyama A, Nagashima T, Iwamoto M, Minota S. Clinical characteristics of lupus enteritis in Japanese patients: the large intestine-dominant type has features of intestinal pseudo-obstruction. Lupus. 2018;27(10):1661-9.

\section{Publisher's Note}

Springer Nature remains neutral with regard to jurisdictional claims in published maps and institutional affiliations.
Ready to submit your research? Choose BMC and benefit from:

- fast, convenient online submission

- thorough peer review by experienced researchers in your field

- rapid publication on acceptance

- support for research data, including large and complex data types

- gold Open Access which fosters wider collaboration and increased citations

- maximum visibility for your research: over $100 \mathrm{M}$ website views per year

At BMC, research is always in progress.

Learn more biomedcentral.com/submissions 